\title{
Adaptation for a Changing Environment: Developing learning and teaching with information and communication technologies
}

\author{
Adrian Kirkwood and Linda Price \\ Institute of Educational Technology \\ The Open University, UK
}

\begin{abstract}
This article examines the relationship between the use of information and communication technologies (ICT) and learning and teaching, particularly in distance education contexts. We argue that environmental changes (societal, educational, and technological) make it necessary to adapt systems and practices that are no longer appropriate. The need to adapt, however, can be perceived as being technology-led and primarily concerned with requiring academic staff to develop their skills in using ICT. We provide a critique of continuing professional development (CPD) for using ICT in teaching and learning that does not entail examining the impact of environmental changes upon the assumptions, goals, and strategies which underlie and shape an organisation's educational practices. In particular, we oppose CPD that concentrates on the individual teacher and their use of ICT. Instead, we contend that professional development should focus upon the scholarship of teaching and learning, and must also reflect the wider organisational context within which ICT is managed and used.
\end{abstract}

Keywords: Organisational learning; conceptions of teaching and learning; information and communication technologies; pedagogical integration; professional development.

\section{Introduction}

This paper examines the complex and frequently misunderstood relationship between the use of information and communication technologies (ICT) and learning and teaching in distance education (DE), particularly at the post-school level. Media and technologies have become essential to the practice of distance education in the 21st century, and are perceived by some as its defining feature (Phipps and Merisotis, 1999). This view might have some validity for the model of distance education that has developed from the North American 'extended classroom.' That type of DE relies upon teacher-led classroom-based activities that are additionally made available to dispersed individuals or groups of learners using videoconferences, streaming media, or other Internet delivered 'virtual classes.' We focus our discussion on the model derived and developed from 'correspondence education,' in which teachers and learners are separated by time as well as by location. This form is practiced by the large-scale, dedicated DE institutions (Daniel, 1996) as well as by many dual-mode universities. In these institutions there is emphasis on achieving economies of scale by the development of materials and resources that asynchronously carry the primary responsibility for teaching students and/ or guiding their learning. 


\author{
Kirkwood \& Price \\ Adaptation for a Changing Environment: \\ Developing learning and teaching with information and communication technologies
}

We argue that basically ICT offers just tools; the means by which important educational outcomes can be achieved. The significance of those tools can be considerable, in that they can enable learners to engage in forms of education that were previously impossible at a distance. However, the adaptation that is necessary in western Higher Education in general (including the expanding DE sector) arises in response to a range of factors that is broader and more farreaching than simply developments in technologies for learning and teaching.

Elsewhere (Kirkwood and Price, 2005) we have argued that technology-led innovations do not in themselves lead to improved educational practices. Too often, it seems, technologies have been introduced to university teaching with little or no consideration being given to the implications for student learning. For example, adding computer-mediated communication to a course will not in itself generate collaborative or co-operative working; neither will it induce dispersed students to form themselves into a learning community. Sept (2004) reflects on how archaeology is taught in the 'information age' in a university in the USA. She comments that although teachers illustrated good use of narrative in their teaching, with a range of media and ICT as support tools, the clear weakness of the culture change was that students were encouraged to memorise the story but gain little understanding of how it was constructed (p. 48). She identifies two problems. First, while students have access to large real data sets and visual raw materials as examples, they have little opportunity to do more than memorise features. Second, students rarely learn to compare or generalise from individual studies to build an integrated understanding of the past. Others too have noted similar problems (Laurillard, 2002; Bostock, 1997). Sept (2004) further comments:

It is ironic that in the so-called Information Age we are still graduating passive, solitary learners poorly equipped to cope with the explosion of information resources competing for their attention (p. 49).

While ICT can enable new forms of teaching and learning to take place, they cannot ensure that effective and appropriate learning outcomes are achieved. It is not technologies, but educational purposes that must provide the lead. This view is not new: the interesting question is why this oftrepeated message, based upon research evidence from many contexts, has failed to have a significant impact in reforming policies and practices.

\title{
Theoretical Framework for Interpreting the Problem
}

Schön (1983) argues that part of the reason that 'reforms' rarely reform derives from the notion that knowledge is molecular: it can be built up from units of information that can be assembled together to form more complicated and advanced knowledge. This leads to a view that it is the business of teachers to communicate this knowledge and the business of students to receive or absorb this knowledge. This is not an outdated view. Prosser, Trigwell, and Taylor (1994) found that university teachers hold a variety of conceptions of learning, and that some of the less sophisticated views encapsulate a transmissive conception of their teaching role. When ICT is adopted by teachers who hold such views of learning, their ICT practices are likely to reflect transmissive approaches that do little to reform or enhance students' experiences of learning, as noted by Sept (2004) in the earlier section.

This issue is further confounded by dissonance between beliefs and practices. Norton and colleagues (Norton, Richardson, Hartley, Newstead, and Mayes, 2005) investigated the variation between academics' beliefs and practices across four higher education institutions in the UK. They found that while academics' conceptions of teaching were orientated towards supporting student learning and problem solving, their actual teaching intentions were oriented towards a knowledge transmission style. This could be interpreted as the difference between what Argyris 
Kirkwood \& Price

Adaptation for a Changing Environment:

Developing learning and teaching with information and communication technologies

and Schön (1974) called espoused theory and theory in use, where the espoused theory is evidenced through the language we use to describe to others what we think we do, while the theory in use is that which is implicit in what we actually do as practitioners and managers. For any individual these might or might not be compatible, although that person may not be aware of any incompatibility. Despite speaking the 'right' language, practitioners and managers might not be following through with practice that is matched.

There is a further problem: that of the reliance of academics upon opinion-based practice (Boyle, 2004). If, as practitioners and managers, we 'think' we are carrying through on our beliefs and conceptions of how to adapt to changing educational environments, but we have no evidence, then this can create a barrier to moving forward with new ideas and, more specifically, with effective use of new technology. Instead, we need to move towards an evidence-based practice in which we actively examine our assumptions, seek evidence as to their effectiveness, and are prepared to change when the evidence indicates this need. Our reflection upon practice, however, needs to go beyond what Argyris and Schön (1978) term single-loop learning. In their model of organisational learning (see Figure 1) they argue that single-loop learning tends to concentrate on using techniques to make strategies more efficient, while factors that underpin those techniques are taken for granted and remain unchallenged.

Figure 1. Single-loop and double-loop organisational learning (based upon Argyris and Schön, 1978).

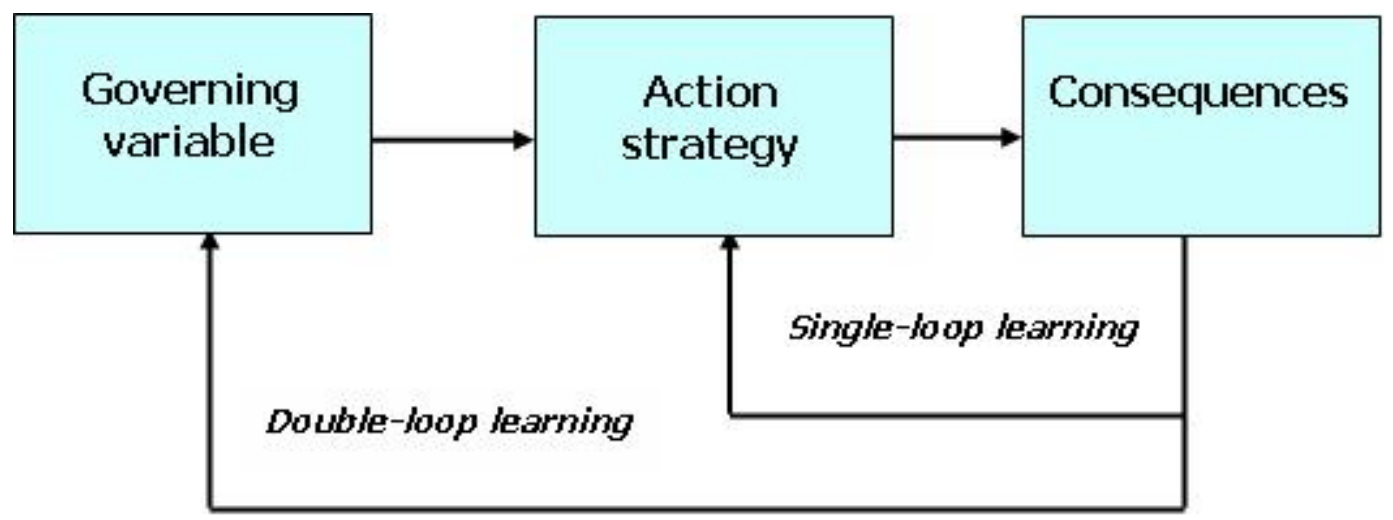

When one strategy is not effective, another one is employed. In contrast, double-loop learning involves questioning the underlying goals, strategies, and assumptions to identify the governing variable(s). This entails detection and correction in ways that necessitate the modification of an organisation's underlying policies and practices. This could explain why the research on effective ICT use is not embedded in mainstream university innovations. Although this problem applies to higher education generally, we will concentrate on how this influences DE and its use of technologies in teaching and learning. This paper examines some of the factors that influence existing policies and practice. It uses the model developed by Argyris and Schön (1978) to interpret the problems and to indicate how professional development activities might address some of these issues.

\section{Factor 1: The influence of historical models}

As one of the earliest providers of multiple media distance education, the UK Open University (UKOU) has had considerable influence on the field. Many aspects of its educational model, 
Kirkwood \& Price

Adaptation for a Changing Environment:

Developing learning and teaching with information and communication technologies

devised in the 1960s and 1970s, have been adopted by other DE providers around the world (Keegan, 1996). Features of the UKOU model were fashioned by the particular social context and technological infrastructure existing in the UK at the time. These shaped the academic practices of the UKOU and have influenced those who have adopted similar models elsewhere. The underpinning assumptions of the model have determined the use of technologies for teaching and learning. Yet the social context and infrastructure varies from institution to institution and changes over time. The major issue that this prompts is the appropriateness of the model for the current context - i.e. the student population and outcomes of learning that it intends to serve. More importantly for the discussion here is how well this model supports the effective integration of ICT.

For example, economies of scale are achieved in large-scale DE universities by adopting an 'Industrial Model' of distance education (Peters, 1983). This separates the preparation of materials and resources for teaching and learning, from the interaction of students with those materials and with their tutor. It also gives preference to the one-way flow of information and ideas - from experts/ teachers to learners - with only limited opportunities for dialogue to take place. In this model the attention of distance educators is focused on the construction of materials rather than on the processes of learning (see early critiques by Harris and Holmes 1976; Northedge, 1976).

One imperative of early DE initiatives was to demonstrate the quality of the educational approach to potential students, employers, and a largely sceptical academic community (Perry, 1976). Planned quality assurance procedures were adopted, involving instructional design methodologies and extensive peer review during the development of courses (inputs), rather than simply quality control of outcomes through student examination. In many cases, this has led to the development of high quality materials that are content rich, but require only a relatively passive involvement of learners.

A further imperative was to develop courses suitable for part-time adult learners, mainly in employment and studying from home. Hence, course materials needed to be self-contained and designed for learning undertaken by individuals who had limited access to library and/ or laboratory facilities. Although a range of technologies, such as books, television/ video and radio/ audio, were used to enhance motivation and to address a range of learning outcomes, they were essentially one-way and transmissive in nature.

The main issue raised by legacy models of DE is whether the largely transmissive (and for students, solitary and passive) nature of this form of education remains appropriate in increasingly networked societies. For example, what role is there for communication technologies that are currently prevalent in the wider social context? If the underlying model of education is one that supports the transmission of knowledge and assesses the acquisition of knowledge by individuals, where is the place for technologies that can support social conceptions of learning and assessment?

It is important for all DE institutions to reflect on their educational models and determine whether they are appropriate for their current circumstances. In order to adopt a double loop approach in relation to the educational use of ICT, there is a need to determine which underlying assumptions are still applicable and which need to be adapted. This should result in a principled approach to developing appropriate policies and practices. 
Kirkwood \& Price

Adaptation for a Changing Environment:

Developing learning and teaching with information and communication technologies

\section{Factor 2: The changing environment for higher education}

Higher education exists within an environment marked by considerable transformations, not only in the education sector but also in wider society. These include the changing characteristics and circumstances of students; new demands in terms of the knowledge, skills, and competencies expected of those gaining certification from courses; greater diversity in relationships between learners and the providers or sources of learning opportunities; and expanding participation in the 'networked society' with its increased opportunities for interpersonal communication and access to digital resources.

Higher education is increasingly being required to support a diverse student body. Calvert (2005) has identified some consequential changes that have occurred in the distance education environment over the last 25 years. These include:

- More distance education players, with the greater involvement of 'conventional' universities and commercial enterprises;

- Institutions are seeking transnational markets for students;

- Collaboration on courses between institutions in different countries.

She also indicates that there is more emphasis on professional and postgraduate courses, particularly for updating and enhancing the knowledge and skills necessary for practitioners in many areas of work.

The changes in the diverse requirements of the student body are accompanied by societal changes. ICT has become part of everyday life for a large proportion of people in the developed and developing world. Socially, people are using the Internet for entertainment, leisure activities, shopping, and information sharing (i.e., the Pew Internet and American Life Project http://www.pewinternet.org/ and the UK National Statistics http://www.statistics.gov.uk/cci/nugget.asp?id=8 ).

Working life for most people in western societies also reflects this growth in ICT use. Businesses and organisations are increasingly using ICT to support their working practices, and to facilitate communication between colleagues and with clients. Many young people entering higher education have grown up with ICT and are hardly aware of the pre-Internet era; they exhibit an 'information-age mindset' (Frand, 2000). Jones (2002) has suggested that some colleges and universities in the USA might be experiencing "an Internet generation gap between professors and students in terms of their Internet usage, interests or abilities” (p. 9). As a consequence, teachers in the western world are no longer the main gatekeepers for information in their area of expertise and this phenomenon, in turn, is challenging the nature of a university academic's role in relation to supporting the student body.

Educational institutions, and those who work in them, need to be constantly reflecting on and investigating the diverse nature of student requirements and their circumstances in order to fully understand the changing higher education environment. However, mainstreaming ICT simply because it reflects societal changes and, perhaps, because it might address the needs of a diverse student body is a flawed strategy: It exemplifies what Argyris and Schön (1978) term single loop organisational learning. In order to determine the governing variable in this situation, institutions need to use an evidence-based approach to assessing the appropriateness and adequacy of their existing models, pedagogic strategies, and policies. This can enable institutions to employ ICTsupported pedagogies that strategically reflect and facilitate high-level educational models and policies required. 
Kirkwood \& Price

Adaptation for a Changing Environment:

Developing learning and teaching with information and communication technologies

\section{Factor 3: Current policies and practices for ICT adoption in higher education}

E-learning policies and strategies for both distance and campus-based education have tended to be technology-driven, concentrating on developing the technological infrastructure at the expense of the underlying pedagogy. A recent survey of ICT implementation in US universities (Zemsky and Massy, 2004) indicates that although course management systems (such as Blackboard and WebCT) have been widely adopted, significant changes in teaching and learning were uncommon as ICT was used mainly to supplement existing practices. Similar findings were reported by Collis and van der Wende (2002) from an international survey. They concluded that much scope remained in terms of exploiting ICT to improve teaching and learning, and for serving learners in different target groups.

In the UK, a recent survey of Managed Learning Environment (MLE) use in Further and Higher Education institutions concluded that “'Enhancing the quality of teaching and learning' is the key driver, identified by almost every institution, for MLE development”, but that "pedagogical issues .... appear to have been of secondary concern until now" (JISC/UCISA, 2003, p. 7). Similarly, formative evaluation of the development programme for the Distributed National Electronic Resource (DNER) revealed that most of the projects lacked a pedagogic rationale and that few project proposals made explicit reference to enhancing student learning (Zenios, Goodyear, and Jones, 2004). For a majority of the projects "there is an assumption that the use of networked technologies will lead to definite educational outcomes and possibly change practice in higher education simply by making resources available to students” (p. 211). The recent e-learning strategy document from the Higher Education Funding Council for England (HEFCE, 2005) supports the view that institutional approaches should focus more on student learning; a welcome shift in emphasis away from the previously dominant technological drivers.

When considering how ICT can be used to support higher education, some teachers think primarily about content or materials. They see ICT in terms of its capacity to store and deliver teaching materials, or its potential role in finding and retrieving dispersed resources. Others think of ICT primarily in terms of the communication that it can facilitate and the dialogue that can be enabled - either synchronously or asynchronously. These two positions can be related to general conceptions of teaching in which the teaching process is seen as being concerned principally either with 'the transmission of knowledge' (teacher-centred) or with 'the facilitation of learning' (learner-centred) (Kember and Kwan, 2000). So how a teacher employs technology relates to what they conceive their teaching role to be.

In dedicated DE universities there has been a drive to get students online to support teaching, learning, and administration. The Internet provides various means to remedy the lack of interpersonal communications that has been "the Achilles heel of distance education" (GuriRosenblit, 2005, p. 475). However, while interpersonal communications can add important new dimensions to the educational experience of distance learners studying independently, there are fundamental problems that the underlying model raises. When courses have been developed for presentation to several cohorts of distance learners over a period of time, it is particularly difficult to introduce radical changes to the model of teaching and learning. Tools and resources can be added to an existing course, but their use by learners is likely to be limited unless they accord with the teaching and learning practices originally conceived for the course.

Many current policies and practices still seem to be technology driven - despite the fact that research and evaluation studies have shown this to be an ill conceived strategy. It appears as though strategies have been employed to use ICT without reflection on the evidence of the 
Kirkwood \& Price

Adaptation for a Changing Environment:

Developing learning and teaching with information and communication technologies

problems that are being addressed. Again this can be understood in terms of the model developed by Argyris and Schön (1978), where the governing variable has not been understood and strategies have been employed merely as a mechanism to change the circumstances without a clear understanding of what circumstances need to be changed and why.

\section{Factor 4: Determinants for learners' use of ICT?}

We have found that the pedagogic model employed and the associated assessment strategies are the primary determinants of what distance learners do in their studies and how they go about it (Kirkwood and Price, 2005). New e-learning opportunities are underutilised and ineffective when they have been appended to courses that are rooted in pedagogic models and practices with which they are not aligned. We have found support for this in reports of studies undertaken at various DE institutions. For example, Erlich, Erlich-Philip, and Gal-Ezer (2005) report that Web resources and communications facilities are little used when added to existing courses. Others have found that just making two-way communication available, such as email or computermediated conferencing (CMC), is unlikely to be sufficient to achieve worthwhile teaching and learning outcomes, especially when it is simply added to an existing course intended for individual study (Fung, 2004; Kear, 2004). If the nature of the course tends to adopt a didactic approach to teaching, where all the materials are supplied and where the assessment policy employs a positivist approach assuming definitive answers, then what pedagogical role would CMC or email have? In a model such as this there is little room for exploiting the pedagogic potential of communications media.

Conversely, when ICT is pedagogically integrated into the course design and adapted for the current environment, it can enable and support enhanced forms of learning (Kirkwood, 2006). For example, if students are required to work in small groups on a collaborative task, where the Internet is used to find information resources, and conferencing or email is used as a means to communicate and construct a joint project which is assessed, then the use of ICT has a clear pedagogic role. These kinds of instantiations, however, are less common than the more superficial uses of ICT that tend to be bolted on to existing course designs.

Teaching and learning in higher education is unlikely to be improved simply by the application of a new technology. As Bates (1995) points out: "Good teaching may overcome a poor choice in the use of technology, but technology will never save poor teaching; usually it makes it worse" (p. 8). We suggest, however, that learning can be enhanced when innovations take into account not only the characteristics of the technology, but also the pedagogic design, the context within which learning takes place, student characteristics and their prior experience, and learners' familiarity with the technologies involved (Kirkwood and Price, 2005). Consequently, students are likely to have a poor educational experience when the focus of the design has been technological as opposed to pedagogical. Hence, it is important to evaluate ICT use and the pedagogical context in which it is used to understand how to effectively use it in future designs.

\section{Factor 5: Students' expectations of teaching and learning}

A further issue arises from students' expectations and conceptions of teaching and learning in higher education. Most learners have only ever experienced full-time schooling when they first enter higher education. Hardly any will have experience of self-managed or self-directed learning, so they might discover a dissonance between their expectations and those of the teaching staff. Kember (2001) found that novice students frequently held a set of beliefs about teaching and learning that could be labelled didactic/ reproductive. The research discovered that: 
Kirkwood \& Price

Adaptation for a Changing Environment:

Developing learning and teaching with information and communication technologies

... students who commence higher education with didactic/ reproductive beliefs can find the process difficult and even traumatic. They are uncomfortable with teaching approaches that do not correspond with their model of teachers presenting information to be passively absorbed by students (p. 217).

The issue here is that students may fail to understand the underlying purpose of some educational activities designed by staff, particularly in relation to ICT use. Hence, an important task for staff is to engender in students an appropriate conception of teaching and learning which provides an educational rationale for learning activities, particularly those that involve the use of technologies.

So, we argue that not only do DE models and systems favour a didactic, materials-centred approach, but also that many students expect to be taught in a transmissive way. Distance educators have a vital role to play in enabling learners to challenge their existing conceptions and to develop more appropriate practices for effective learning. Understanding these difficulties is far more fundamental to the success of a student than the use of ICT per se.

\section{Factor 6: The adequacy of professional development for teaching and learning with ICT?}

One of the main problems with current professional development practices in relation to ICT is the concentration of effort on the technological aspects. As a result, professional development for academic staff has largely focused on developing teachers' technical skills (Ho, Watkins, and Kelly, 2002). Consequently ICT has tended to be used tactically, mainly to supplement existing teaching practices rather than having any transformative effect in response to the changing environment. Garrison and Anderson (2000) refer to these as 'weaker' and 'stronger' technological influences respectively. Without opportunities for reflection upon existing practices and why they might require adaptation, a poor understanding of how and why students might use ICT effectively in learning can result.

Although some examples of good practice have been identified (Epper and Bates, 2001), many CPD programmes in relation to ICT appear devoid of underlying considerations regarding the nature of teaching. Williams (2003) conducted a Delphi study of DE practitioners to determine roles and competencies for distance education programmes in higher education that could be used to inform the design of CPD activities. Of the 30 general competencies agreed and ranked by the panel of expert participants, only eight were categorised as being concerned with 'learning and instruction.' Most of those addressed specific skills and techniques: few were directly related to understanding the nature of learning and teaching, and there was no mention of how such issues impact on the effective use of technologies.

Harvey and Knight (1996) argue that professional development should be understood as the scholarship of teaching. This requires teachers to reflect on their own teaching beliefs and practices. Higher education teachers hold a variety of conceptions of teaching and these in turn influence their approach (Prosser, Trigwell, and Taylor, 1994; Trigwell and Prosser, 1996). ICT can support varying conceptions of teaching, the problem is that less sophisticated conceptions and approaches to teaching become more visible in a technologically rich learning environment. Often it is not the technology that is failing, but the actual teaching and pedagogical approach (Laurillard, 2002). 
Kirkwood \& Price

Adaptation for a Changing Environment:

Developing learning and teaching with information and communication technologies

The problem is further compounded by suspicions about the goals of professional development and its focus on the individual. Teachers often regard it as a managerialist tool to re-educate the workforce in order to meet management targets. Engaging teachers in reflecting upon their practices is an activity that is recognised as being difficult. It requires time and effort on the part of the institution to embed and support such an approach while also dealing with some hostility from staff who may find an introspection of their entrenched and often traditional views of teaching beliefs deeply uncomfortable.

We have already drawn attention to the lack of congruence between teachers' beliefs and practices (Norton, et al, 2005). Differences in teaching intentions across different institutions seem to result from contextual factors that may require an individual teacher's practices to conform to the dominant teaching culture. The framework for improving student learning developed by Price and Richardson (2004) argues that the institutional and professional context impacts upon approaches to teaching. Prosser, Ramsden, Trigwell, and Martin (2003) similarly argue that context is related to both to students' and teachers' conceptions, which in turn relate to their approaches to learning and teaching, respectively.

A second main problem with current professional development practices is that they often target individual teachers or support staff. In DE institutions, courses tend to be produced by a group of people, not all of whom will be academics. Yet, to date, there has been no research into the teaching conceptions of individuals within a course team environment and how the interaction of varying conceptions of teaching impacts on the overall pedagogical design and philosophy of the course. Subsequently institutions may adopt the 'safe and easy' option and try to change the content and how it is delivered, rather than considering more fundamental issues such as teachers' conceptions and approaches to teaching, how this impacts on group course production, and how the course pedagogy can be transformed using ICT. This leads to CPD activities that are aimed at preparing individual teachers to make more effective use of ICT and that focus largely on pedagogical tactics.

Hence, CPD activities need to go beyond the individual teacher and address departmental, faculty, and institutional views of teaching and their rationales for incorporating ICT into course programmes. Too often it seems that institutional strategies create barriers that impede innovations to enhance student learning (Hockings, 2005). Managers too need to engage in relevant CPD activities in order to understand the implications of particular ICT use in course designs and to engage in developing policies that consider the wider organisational context. This approach supports the notion of double-loop organisational learning (Argyris and Schön, 1978), where the goal is to engage in understanding the underlying governing variable of any set of circumstances before developing strategies to address them.

\section{Discussion}

The model proposed by Argyris and Schön (1978) offers some explanation as to why the oftrepeated message, that ICT use needs to be pedagogically driven to be effective, is failing to have an impact. It appears that in many cases strategies have been employed to change a set of circumstances rather than fully investigate the governing variable and then developing appropriate strategies. Without an evidence-based approach we cannot be certain that our strategies, policies, and practices in education are focused on the issues that need to be addressed.

Professional development has often been seen as the method of addressing the 'perceived' failures of an institution. This too appears to be an inadequate strategy. The ability of an institution to adapt to a changing environment and effectively developing teaching and learning 
Kirkwood \& Price

Adaptation for a Changing Environment:

Developing learning and teaching with information and communication technologies

with ICT, has to go beyond the remit of assuming that professional development activities alone will solve the problem. As we have articulated in this paper there are many pressing factors that DE institutions face in today's educational climate, such as changes in the social context, outdated models of DE, the changing HE environment, the appropriateness of current policies and practice and, last but not least, students' expectations of education. While EPD activities can address some of these issues, they cannot effect change in a vacuum. Institutions need to review and investigate the factors facing them, and use the evidence to develop appropriate policies and practices to address them in a holistic manner.

Professional development policies and practices might also need to be transformed. In some instances professional development is perceived as a remedial activity designed to align teaching staff to new working practices imposed from above, or to 'correct' errant academics. This needs to be addressed in two ways. First, professional development activities need to go beyond the individual and adopt a holistic approach to development that includes departmental, faculty, and senior university managers. In addition to teachers and support staff, managers need to be included in a range of professional development activities relating to teaching and learning with ICT in order that they understand the implications of their policies and practices. This should help engender an evidence-based and genuinely developmental approach to policy development practices in order to adapt appropriately to the changing HE environment.

Second, the focus needs to be on underlying pedagogical theories and practices and their effects in particular educational contexts. This involves examining the fundamental assumptions and goals to enable appropriate strategies to evolve and in order to avoid the 'tips and tactics' approach that tends to promote superficial professional development activities manifest in technically oriented training.

\section{Conclusion}

All educational institutions need to adapt in order to survive and that is particularly true for DE, which serves a diverse student population with a broad array of needs and circumstances. Educational provision is changing significantly and distance educators have a leading role to play in developing flexible programmes for prospective students coming from a variety of backgrounds, contexts, and geographical locations. To fulfill this remit successfully, we must understand how to harness technology in ways that provide an effective educational experience for the students we hope to serve. The underpinning argument of this paper has been that technology must provide the tools rather than the drivers for achieving core educational outcomes. If technologies are to be used purposefully to enhance student learning they need to be integrated not just in terms of pedagogical tactics, but must also reflect and align with the fundamental educational philosophy and aims. DE operates within a changing environment which impacts on an institution's aspirations and operations in many and varied ways, so it is necessary to regularly review and reassess the assumptions and models that underlie educational policies and practices. Successful adaptation and change involving the use of ICT necessitates more than simply replicating or supplementing existing teaching practices: everything governing those practices must be reconsidered and reflected upon. This requires a holistic view of the institution's policies, practices, and professional development activities.

Course development and presentation is rarely confined to an individual or small group of staff and decision-making can be complex and have unexpected repercussions. The model for using ICT in future DE programmes must encompass and develop policies that recognise both the educational rationale for, and the implications of, ICT use. To support such transformations, professional development programmes need to go beyond 'tips and tactics' for the individual and 
Kirkwood \& Price

Adaptation for a Changing Environment:

Developing learning and teaching with information and communication technologies

encompass a more theoretically driven understanding of the educational rationale and consequences for ICT use with a wide range of staff and senior managers.

\section{References}

Argyris, C., and Schön, D. (1974). Theory in Practice: Increasing professional effectiveness. San Francisco: Jossey-Bass.

Argyris, C., and Schön, D. (1978). Organizational Learning: A theory of action perspective. Reading, MA.: Addison Wesley.

Bates, A. W. (1995). Technology, Open Learning and Distance Education. London: Routledge.

Bostock, S. J. (1997). Designing web-based instruction for active learning. In B. H. Khan (Ed.) Web-based instruction (p. 225-230). Englewood Cliffs, NJ.: Educational Technology Publications.

Boyle, T. (2004). Technology and the reflective practitioner. In A. Irons and S. Alexander (Eds.) Effective Learning and Teaching in Computing (p. 182-188). London: RoutledgeFalmer.

Calvert, J. (2005). Distance Education at the Crossroads. Distance Education 26(2), 227-238.

Collis, B., and van der Wende, M. (Eds.) (2002). Models of Technology and Change in Higher Education. Center for Higher Education Policy Studies, University of Twente, The Netherlands. Retrieved October 20, 2003 from: http://www.utwente.nl/cheps/documenten/ictrapport.pdf

Daniel, J. S. (1996). Mega-Universities and the Knowledge Media. London: Kogan Page.

Epper, R. M. and Bates, A. W. (2001). Teaching Faculty How to Use Technology, Westport, CT.: American Council on Education/Oryx Press.

Erlich, Z., Erlich-Philip, I., and Gal-Ezer, J. (2005). Skills Required for Participating in CMC Courses: An empirical study. Computers \& Education 44(4), 477-487.

Frand, J. L. (2000). The Information Age Mindset. EDUCAUSE Review, September/October, 1424. Retrieved March 23, 2006 from: http://www.educause.edu/ir/library/pdf/ERM0051.pdf

Fung, Y. H. (2004). Collaborative Online Learning: Interaction patterns and limiting factors, Open Learning 19(2), 135-149.

Garrison, R., and Anderson, T. (2000). Transforming and enhancing university teaching: stronger and weaker technological influences. In T. Evans and D. Nation (Eds.) Changing University Teaching (p. 24-33). London: Kogan Page.

Guri-Rosenblit, S. (2005). 'Distance Education' and 'e-Learning': Not the same thing. Higher Education 49(4), 467-493. 
Kirkwood \& Price

Adaptation for a Changing Environment:

Developing learning and teaching with information and communication technologies

Harris, D., and Holmes, J. (1976). Open-ness and control in higher education: towards a critique of the Open University. In R. Dale, G. Esland and M. MacDonald (Eds.) Schooling and Capitalism: A sociological reader. London: Routledge and Kogan Page.

Harvey, L., and Knight, P. T. (1996). Transforming Higher Education. Buckingham, UK.: SRHE and Open University Press.

Higher Education Funding Council for England (HEFCE) (2005). HEFCE strategy for e-learning. Bristol, UK.: Higher Education Funding Council for England. Retrieved April 29, 2005 from: http://www.hefce.ac.uk/pubs/hefce/2005/05_12/

Ho, A., Watkins, D., and Kelly, M. (2001). The Conceptual Change Approach to Improving Teaching and Learning: An evaluation of a Hong Kong staff development programme. Higher Education 42(2), 143-169.

Hockings, C. (2005). Removing the Barriers? A study of the conditions affecting teaching innovation. Teaching in Higher Education 10(3), 313-326.

Joint Information Systems Committee (JISC) and the Universities and Colleges Information Systems Association (UCISA) (2003). Managed Learning Environment Activity in Further and Higher Education in the UK. Retrieved September 5, 2006 from: http://www.jisc.ac.uk/uploaded_documents/mle-study-final-report.pdf

Jones, S. (2002). The Internet Goes to College. A September 15 Report from the Pew Internet and American Life Project. Retrieved March 23, 2006 from: http://207.21.232.103/pdfs/PIP College Report.pdf

Kear, K. (2004). Peer Learning Using Asynchronous Discussion Systems in Distance Education. Open Learning 19(2), 151-164.

Keegan, D. (1996). Foundations of Distance Education (3rd Ed.). London: Routledge.

Kember, D. (2001). Beliefs about Knowledge and the Process of Teaching and Learning as a Factor in Adjusting to Study in Higher Education. Studies in Higher Education 26(2), 205-221.

Kember, D., and Kwan, K. P. (2000). Lecturers' approaches to teaching and their relationship to conceptions of good teaching. Instructional Science 28(5), 469-490.

Kirkwood, A. (2006). Going outside the box: skills development, cultural change and the use of on-line resources. Computers and Education 47(3), 316-331.

Kirkwood, A., and Price, L. (2005). Learners and Learning in the 21st Century: What do we know about students' attitudes and experiences of ICT that will help us design courses? Studies in Higher Education 30(3), 257-274.

Laurillard, D. (2002). Rethinking University Teaching (2nd Ed.) London: Routledge.

Northedge, A. (1976). Examining our implicit analogies for learning processes. Programmed Learning and Educational Technology 13(4), 67-78. 
Kirkwood \& Price

Adaptation for a Changing Environment:

Developing learning and teaching with information and communication technologies

Norton, L., Richardson, J. T. E., Hartley, J., Newstead, S., and Mayes, J. (2005). Teachers'

Beliefs and Practices Concerning Teaching in Higher Education. Higher Education 50(4), 537-571.

Perry, W. (1976). Open University. Milton Keynes, UK.: The Open University Press.

Peters, O. (1983). Distance education and industrial production: a comparative interpretation in outline. In D. Sewart, D. Keegan and B. Holmberg (Eds.) Distance Education: International perspective. London: Croom Helm.

Pew Internet and American Life Project (n.d.). Pew Internet and American Life Project website portal. Retrieved August 29, 2006 from: http://www.pewinternet.org/

Phipps, R., and Merisotis, J. (1999). What's the Difference? A review of contemporary research on the effectiveness of distance learning in higher education. Washington DC.: Institute for Higher Education Policy. Retrieved August 4, 2003 from: http://www.ihep.org/Pubs/PDF/Difference.pdf

Price, L., and Richardson, J. T. E. (2004). Why is it difficult to improve student learning? In C. Rust (Ed.) Proceedings of the 11th Improving Student Learning Symposium, Improving Student Learning: Theory, Research and Scholarship (p. 105-120). Oxford: The Oxford Centre for Staff and Learning Development.

Prosser, M., Ramsden, P., Trigwell, K., and Martin, E. (2003). Dissonance in Experience of Teaching and its Relation to the Quality of Student Learning. Studies in Higher Education 28(1), 37-48.

Prosser, M., Trigwell, K., and Taylor, P. (1994). A phenomenographic study of academics' conceptions of science learning and teaching. Learning and Instruction 4(3), 217-232.

Schön, D. A. (1983). The Reflective Practitioner: How professionals think in action. New York: Basic Books.

Sept, J. (2004). The Stone Age in the Information Age. In W. E. Becker and M. L. Andrews (Eds.) The Scholarship of Teaching and Learning in Higher Education (p. 47-80). Bloomington, IN.: Indiana University Press.

Trigwell, K., and Prosser, M. (1996). Changing Approaches to Teaching: A Relational Perspective. Studies in Higher Education 21(3), 275-284.

UK National Statistics Online (n.d.). UK National Statistics website portal. Retrieved August 30, 2006 from: http://www.statistics.gov.uk/cci/nugget.asp?id=8

Williams, P. E. (2003). Roles and Competencies for Distance Education Programs in Higher Education Institutions. American Journal of Distance Education 17(1), 45-57.

Zemsky, R., and Massy, W. F. (2004). Thwarted Innovation: What Happened to e-learning and Why? A report from The Learning Alliance, University Pennsylvania. Retrieved August 10, 2004 from: http://www.irhe.upenn.edu/WeatherStation.html 
Kirkwood \& Price

Adaptation for a Changing Environment:

Developing learning and teaching with information and communication technologies

Zenios, M., Goodyear, P., and Jones, C. (2004). Researching the impact of the networked information environment on learning and teaching. Computers and Education 43(1-2), 205-213.

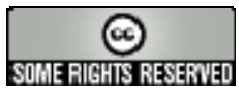

Athabasca University 